Article

\title{
Time Series Analysis of MODIS-Derived NDVI for the Hluhluwe-iMfolozi Park, South Africa: Impact of Recent Intense Drought
}

\author{
Nkanyiso Mbatha ${ }^{1, *}$ and Sifiso Xulu ${ }^{1}$ \\ 1 Department of Geography and Environmental Studies, University of Zululand, KwaDlangezwa, 3886, \\ South Africa; mbathanb@unizulu.ac.za (N.M.); xulusi@unizulu.ac.za (S.X.) \\ * Correspondence: mbathanb@unizulu.ac.za; Tel.: +27-035-902-6400
}

\begin{abstract}
The variability of meteorological parameters such as temperature and precipitation, and climatic conditions such as intense droughts, are known to impact vegetation health over southern Africa. Thus, understanding large-scale ocean-atmospheric phenomena like the El Niño/Southern Oscillation (ENSO) and Indian Ocean Dipole/Dipole Mode Index (DMI) is important as these factors drive the variability of temperature and precipitation. In this study, 16 years (2002-2017) of Moderate Resolution Imaging Spectroradiometer (MODIS) Terra/Aqua 16-day normalized difference vegetation index (NDVI), extracted and processed using JavaScript code editor in the Google Earth Engine (GEE) platform in order to analyze the response pattern of the oldest proclaimed nature reserve in Africa, the Hluhluwe-iMfolozi Park (HiP), during the study period. The MODIS-enhanced vegetation index and burned area index were also analyzed for this period. The area-averaged Modern Retrospective Analysis for Research Application (MERRA) model maximum temperature and precipitation were also extracted using the JavaScript code editor in the GEE platform. This procedure demonstrated a strong reversal of both the NDVI and Enhanced Vegetation Index (EVI), leading to signs of a sudden increase of burned areas (strong BAI) during the strongest El Niño period. Both the Theilsen method and the Mann-Kendall test showed no significant greening or browning trends over the whole time series, although the annual MannKendall test, in 2003 and 2014-2015, indicated significant browning trends due to the most recent strongest El Niño. Moreover, a multi-linear regression model seems to indicate a significant influence of both ENSO activity and precipitation. Our results indicate that the recent 2014-2016 drought altered the vegetation condition in the HiP. We conclude that it is vital to exploit freely available GEE resources to develop drought monitoring vegetation systems, and to integrate climate information for analyzing its influence on protected areas, especially in data-poor counties.
\end{abstract}

Keywords: Drought; NDVI; ENSO; Wavelet; Time Series Analysis; Hluhluwe-iMfolozi Park; Google Earth Engine

\section{Introduction}

Vegetation within protected areas such as game reserves provides wildlife and society with indispensable ecosystem goods and services [1] including food, medicinal resources, aesthetic value, and recreational opportunities [2]. However, inappropriate management and other disturbances affect the potential productivity and spatial extent of this resource [3]. Thus, any factor that poses a threat to vegetation and its associated benefits which could affect their productivity in the protected areas needs to be identified and monitored. One such threat is increase in temperature above normal as well as a prolonged decline in precipitation and soil moisture, leading to extreme climatic events such as droughts, which severely affect vegetation productivity [4]. Drought-related impacts are becoming more multifaceted, as explained by their rapidly growing consequences in sectors such as recreation and tourism, agriculture, and energy [5]. 
The influence of drought on vegetation varies in spatial and temporal scales, and these are projected to increase with climate change [6,7]. This behavior affects wildlife, particularly in semiarid and arid environments where herbivory is strongly restricted by vegetation extent and water availability [8]. In the north-east corner of KwaZulu-Natal, South Africa, for example, droughts are becoming a recurrent and prominent feature $[9,10]$, affecting vegetation, water and wildlife resources notably in the Hluhluwe-iMfolozi Park (HiP), the oldest proclaimed game reserve in Africa, as reported in this paper. Furthermore, these impacts have potential consequences that could incapacitate this game reserve's support of its specialist grazers such as rhinos [11].

Understanding the association between vegetation productivity and climatic variables such precipitation and temperature has therefore become a high priority. To address this, spatiotemporal tools that can integrate climate data with other information of interest are required. Remotely sensed data provide the opportunity to monitor vegetation dynamics in a systematic manner [12]. They play a growing role in drought detection and management as they afford up-to-date information over various time and geographic scales and complement alternative techniques such as field surveys [4] and interviews [13]. Remote sensing's systematic observation allows us to track vegetation conditions from the 1970s to the present [14] and provides the means to integrate the record with causal factors. Several drought studies based on satellite-derived normalized difference vegetation index (NDVI) have enhanced our understanding of how vegetation reacts to drought events over time [15-18]. The index is the ratio of the difference between the near-infrared and red bands of the spectrum over the sum of the near-infrared and red bands [19,20] and is a robust indicator of vegetation condition [21].

Hitherto, numerous studies have explored vegetation changes using NDVI in response to climatic variability. Most have shown that vegetation is largely swayed by the El Niño/Southern Oscillation (ENSO) phenomenon and have been established to respond well to climatic variables [10, $17,22,23]$. These studies in different climatic regions have revealed climate-induced effects in key economic sectors such agriculture [24] and forestry [17, 25]. Most recently, Huang et al. [26] used MODIS-derived NDVI to demonstrate how vegetation responds to climate variation in the ZiyaDaqing basins of China. Their results showed that the trends of growing season NDVI were significant in the forest, grassland and highlands of Taihang but insignificant in most plain drylands [23]. They also showed how grassland, as the primary vegetation on the Qinghai-Tibet Plateau, has been increasingly influenced by water availability due to droughts over the last decade.

Several factors make the HiP an ideal site for assessing the effects of drought on wildlife. First, Bond et al. [27] established that drought largely influences the extent of grazing vegetation in the reserve. More recently, Xulu et al. [10] showed how the recent intense drought moderated the vegetation health of commercial plantations located $\sim 60 \mathrm{~km}$ from the park. Second, the HiP is an important conservation area and ecotourism destination in South Africa [28], so that the resultant socio-economic impacts of ecosystem changes are of great concern. In this study, therefore, we aim to evaluate the influence of climatic variability on vegetation in the game reserve over the period 2002 to 2017. This is the first attempt to demonstrate the spatial dimension of the drought effects in the HiP using satellite data. We show how to construct a MODIS-derived NDVI time series in the GEE platform, and perform statistical tests to determine the causal influence of climatic variables in the reserve.

\section{Materials and Methods}

\subsection{Study Area}

This study was conducted at the Hluhluwe-iMfolozi Park, which covers $900 \mathrm{~km}^{2}$ and extends between $28^{\circ} 00^{\prime} \mathrm{S}$ and $28^{\circ} 26^{\prime} \mathrm{S}$, and $31^{\circ} 43^{\prime} \mathrm{E}$ and $32^{\circ} 09^{\prime} \mathrm{E}$ in northern KwaZulu-Natal, South Africa (Figure 1). The reserve is managed by Ezemvelo KwaZulu-Natal Wildlife (EKZN Wildlife). The landscape is undulating with altitude ranging from approximately 50 to 500 m.a.s.l and comprises a mixture of soil types resulting from topographic and climatic heterogeneity [29]. The terrain of the study area on the right side of Figure 1 was plotted using the Global Multi-resolution Terrain 
Elevation Data 2010 data set. The version of this data is the Breakline Emphasis, 7.5 arc-seconds, and is archived as USGS/GMTED2010 in the Google Earth Engine (GEE) JavaScript platform.

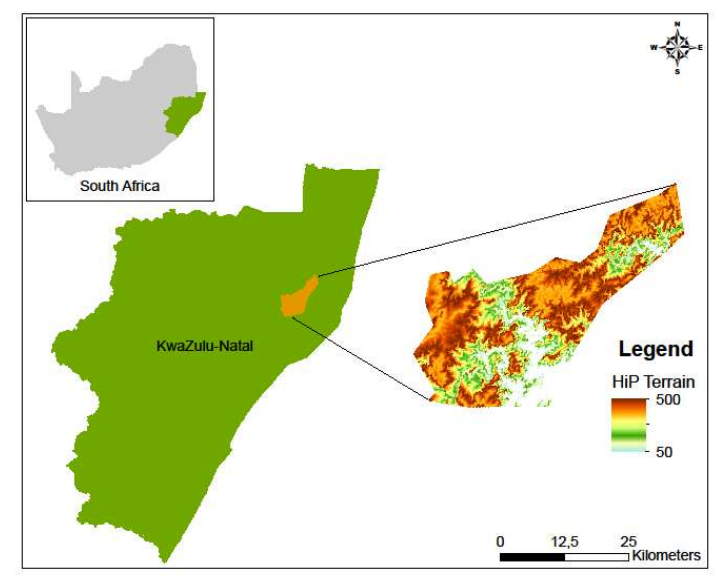

Figure 1. Study area showing the Hluhluwe-iMfolozi Park in the north-eastern part of South Africa.

Two main rivers, the Black and White Umfolozi, pass through this region. The entire area of the park is fenced and borders on populated rural communities. Vegetation varies from semi-deciduous forest in the north of Hluhluwe to open savanna woodland in the southern iMfolozi. Much of the area is dominated by woodland savanna interspersed with shrub thicket [30]. The climate is subtropical with summer rainfall. It receives a mean annual rainfall ranging from 700 to $985 \mathrm{~mm}$, much of it occurring between October and March [31]. The park supports approximately 1200 plant species, including 300 tree and 150 grass species.

\subsection{Data}

In order to investigate the variability of vegetation in the HiP in response to climatic conditions as well as the recent intense drought of 2014-2016, we opted to use the monthly averaged MODIS Terra/Aqua 16-day data sets measured for the period from 2002 to 2017 (16 years). With its considerable time resolution compared to other satellites, and its spatial resolution of $500 \mathrm{~m}$, MODIS images were the most appropriate for this study because of the size of the geographic area. The MODIS data used here are archived in the GEE as image collection. This data product is generated from a MODIS/MCD43A4 version 6 surface reflectance composite. More details about the MCD43A4 MODIS/Terra and Aqua nadir BRDF-adjusted reflectance daily level 3 global $500 \mathrm{~m}$ SIN grid V006 data can be found in a study by Schaaf et al. [32]. The data were extracted and processed using the JavaScript code editor in the GEE platform (https://earthengine.google.com/)(see Appendix A), which provides possibilities of parallel computing and large data processing for even very large study areas. For the purpose of this investigation, our main parameter is the NDVI, but we also considered other vegetation indices such as the Enhanced Vegetation Index (EVI) and Burned Area Index (BAI). The BAI was also included in order to determine the possible vegetation burning activity, which may have been triggered by drier conditions associated with an intense drought period. These spectral indices were calculated using the formulas:

$$
\begin{gathered}
N D V I=\frac{N I R-R}{N I R+R} \\
E V I=2.5 \frac{N I R-R}{N I R-6 R-7.5 B+1}
\end{gathered}
$$




$$
B A I=\frac{1}{(0.1+R)^{2}+(0.06+N I R)}
$$

where R and NIR are spectral bands in the blue (450-500 nm), red $(600-700 \mathrm{~nm})$ and near-infrared (700-1300 $\mathrm{nm}$ ) regions.

The GEE also archives climate data, which include temperature and precipitation. In our study, we derived the maximum temperature and precipitation values averaged for the study area for the period from 2002 to 2017 using the Climate Engine Application (CEA, http://climateengine.org/). The climate data used here are an output of the Modern Retrospective Analysis for Research Application (MERRA-2) model [33]. The MERRA model is an American global reanalysis tool operating from 1979 onwards that is based on the National Aeronautics and Space Administration (NASA) Goddard Earth Observation serving Data Assimilation System version 5 (GEOS-5). The MERRA-2 model data are given at a spatial resolution of $0.67^{\circ} \times 0.50^{\circ}$ at 1-hourly to a 6-hourly intervals.

The ENSO phenomenon influences rainfall and temperature conditions largely over southern Africa [34, 35]. Previous studies have demonstrated how vegetation responds significantly to ENSO [35] and the DMI [36] index as a measure of climatic conditions [37-39] in some parts of southern Africa. Thus, in order to investigate changes in vegetation in the HiP due to variability in climatic conditions, it is important to consider these other climate indices. In this study, we used Niño3.4 monthly mean time series retrieved from the National Oceanic and Atmospheric Administration (NOAA) website (https://www.esrl.noaa.gov/psd/gcos_wgsp/Timeseries/). The Niño3.4 index is calculated by taking the area-averaged sea-surface temperature (SST) within the Niño3.4 region, which is at $5^{\circ} \mathrm{N}-5^{\circ} \mathrm{S}$ longitude and $120^{\circ} \mathrm{W}-170^{\circ} \mathrm{W}$ latitude in the Pacific Ocean. On the other hand, the DMI is calculated by taking the difference between the SST anomalies in the western $\left(50^{\circ} \mathrm{E}-70^{\circ} \mathrm{E}\right),\left(10^{\circ} \mathrm{S}-\right.$ $\left.10^{\circ} \mathrm{N}\right)$ and eastern $\left(90^{\circ} \mathrm{E}-110^{\circ} \mathrm{E}\right),\left(10^{\circ} \mathrm{S}-0^{\circ} \mathrm{N}\right)$ sectors of the equatorial Indian Ocean [36]. The DMI data were downloaded from the website: http://www.jamstec.go.jp/frcgc/research/d1/iod/iod/dipole_mode_index.html. The relevant time series of Niño3.4 and DMI are shown in Figure 2.

\subsection{Multiple-linear Regression}

One of the principal objectives of this study was to quantify the effects of temperature, precipitation, ENSO and DMI on the NDVI as a surrogate for vegetation in the study area. Multiplelinear regression analysis (MLR), which is commonly used to explain the relationship between one continuous dependent variable and two or more independent variables, was employed. The MLR model output of a number $n$ observations can be represented as:

$$
y_{i}=\beta_{0}+\beta_{1} x_{i 2}+\cdots+\beta_{p} x_{i p}+\varepsilon_{i} \text { where } i=1,2,3, \ldots, n
$$

where $y_{i}$ is the dependent variable (NDVI in this case), $x_{i p}$ represents the independent variables (temperature, precipitation, Niño3.4 and DMI in this case), $\beta_{0}$ is the intercept, and $\beta_{1}, \beta_{2}, \ldots \beta_{p}$ are the coefficients of the $x$ terms. The term $\varepsilon_{i}$ represents the error term, which the model always tries to minimize.

\subsection{Mann-Kendall Test}

It is always useful to assess the monotonic trends in a time series of any geophysical data. In this study, the Mann-Kendall test [40-42] was used. This is a non-parametric rank-based test method, which is commonly used to identify monotonic trends in time series of climate data, environmental data or hydrological data. Non-parametric methods are known to be resilient to outliers [43], hence it is desirable to choose such methods. Based on a study by Kendall [42] and recently by Pohlert [44] and others, the Mann-Kendall test statistic is calculated from the formula: 


$$
S=\sum_{k=1}^{n-1} \sum_{j=k+1}^{n} \operatorname{sign}\left(X_{j}-X_{k}\right)
$$

where

$$
\operatorname{sign}(x)= \begin{cases}+1, & \text { if } x>1 \\ 0, & \text { if } x=0 \\ -1, & \text { if } x<1\end{cases}
$$

The average value of $S$ is $E[S]=0$, and the variance $\sigma^{2}$ is given by the equation:

$$
\sigma^{2}=\left\{n(n-1)(2 n+5)-\sum_{j=1}^{p} t_{j}\left(t_{j}-1\right)\left(2 t_{j}+5\right)\right\} / 18
$$

where $t_{j}$ is the number of data points in the $j^{\text {th }}$ tied group, and $p$ is the number of the tied group in the time series. It is important to mention that the summation operator in the above equation is applied only in the case of tied groups in the time series, to reduce the influence of individual values in tied groups in the ranked statistics. On the assumption of random and independent time series, the statistic $S$ is approximately normally distributed provided that the following z-transformation equation is used:

$$
Z= \begin{cases}\frac{S-1}{\sigma} & \text { if } S>1 \\ 0 & \text { if } S=0 \\ \frac{S+1}{\sigma} & \text { if } S<1\end{cases}
$$

The value of the $S$ statistic is associated with the Kendall $\tau=\frac{S}{D}$ where

$$
D=\left[\frac{1}{2} n(n-1)-\frac{1}{2} \sum_{j=1}^{p} t_{j}\left(t_{j}-1\right)\right]^{1 / 2}\left[\frac{1}{2} n(n-1)\right]^{1 / 2}
$$

In regard to the $\mathrm{z}$-transformation equation defined above, this study considered a 5\% confidence level, where the null hypothesis of no trend was rejected if $|z|>1.96$. Another important output of the Mann-Kendall statistic is the Kendall $\tau$ term, which is a measure of correlation which indicates the strength of the relationship between any two independent variables. In this study, the MannKendall test system summarized above was applied to the NDVI data by writing a piece of code in R-project and following the instructions by Pohlert [44].

\subsection{Wavelet Transforms and Wavelet Coherence}

We opted to employ the wavelet transform analyses method [45] because of its ability to obtain a time-frequency representation of any continuous signal. Basically, the continuous wavelet transform (CWT) of a given geophysical (in this case) time series is given by transforming the time series into time and frequency space. Whereas there are several types of wavelets, the choice of the wavelet function is determined by the data series, of which for geophysical data the Morlet wavelet function has been shown to perform well [45-47]. Thus, the CWT [ $\left.W_{n}(\mathrm{~s})\right]$ for a given time series $\left(x_{n}\right.$, $n=1,2,3 \ldots N)$ with respect to wavelet $\Psi_{0}(\eta)$ is defined as: 


$$
W_{n}^{X}(s)=\sum_{n^{\prime}-1}^{n-1} X_{n^{\prime}} \Psi^{*}\left[\frac{\left(n^{\prime}-n\right)}{s} \delta t\right]
$$

where $s$ is the wavelet scale, $n^{\prime}$ is the translated time index, $n$ is the localized time index, and $\Psi^{*}$ is the complex conjugate of the normalized wavelet. $\delta t$ is the uniform time step (which is months in this case). The wavelet power is calculated from $\left|W_{n}(n)\right|^{2}$. In our study, the CWT statistical significance at a $95 \%$ confidence level was estimated against a red noise model [45, 47]. Using continuous wavelet transform analysis, it is also possible to quantify the relationship between two independent time series of the same time step $\delta t$. In this study, the aim was to quantify the relationship between NDVI averaged for the study area and DMI, Niño3.4, maximum temperature, and precipitation time series. Following Grinsted et al. [47], for the two time series of $X$ and $Y$, with different CWT $W_{n}^{X}(s)$ and $W_{n}^{Y}(s)$ values, the cross-wavelet transform $W_{n}^{x y}(s)$ is given by

$$
W_{n}^{X Y}(s)=W_{n}^{X}(s) W_{n}^{Y *}(s)
$$

where $^{*}$ represents the complex conjugate of the $\mathrm{Y}$ time series. The output of the above equation can also assist in calculating the wavelet coherence. Basically, wavelet coherence is a measure of the intensity of the covariance of the two time series in a time-frequency domain. This is an important parameter because the cross-wavelet gives only a common power. Another important process is to calculate the phase difference between the two time series. Here, the procedure is to estimate the mean and confidence interval of the phase difference. Following a study by Grinsted et al. [47], we used the circular mean of the phase over regions with relatively high statistical significance that are inside the cone of influence (COI) to quantify the phase relationship between any two independent time series. As defined in a study by Zar [48] and also later by Grinsted et al. [47], the mean circulation of a set of angles $\left(a_{i}, I=1,2,3 \ldots n\right)$ can be defined by the equation:

$$
a_{m}=\arg (X, Y) \text { with } X=\sum_{i=1}^{n} \cos \left(a_{i}\right) \text { and } Y=\sum_{i=1}^{n} \sin \left(a_{i}\right)
$$

Following studies by Torrence et al. [45, 47], the wavelet coherence between two independent time series can be calculated using the equation:

$$
R_{n}^{2}(s)=\frac{\left|S\left(s^{-1} W_{n}^{X Y}(s)\right)\right|^{2}}{S\left(s^{-1}\left|W_{n}^{X}(s)\right|^{2}\right) \times S\left(s^{-1}\left|W_{n}^{Y}(s)\right|^{2}\right)}
$$

where the parameter $S$ is the smoothing operator defined by $S\left(W_{n}(s)\right)=S_{\text {scale }}\left[S_{\text {time }}\left(W_{n}(s)\right)\right]$. The parameter $S_{\text {time }}$ represents the smoothing in time. For further details about the theory of wavelet analyses, the reader is referred to $[45,47,49]$.

\section{Results and Discussion}

To investigate whether the El Niño event of 2014-2016 can be classified as strong, a time series for the period from the beginning of the satellite era (1980) to the year 2017 was plotted (see Figure 2a). We also considered the DMI index (Figure 2b) as a measure of climatic conditions of the eastern part of southern Africa [38]. A general classification of ENSO events should contain 5 consecutive overlapping 3-month periods with SST anomalies below -0.5 for the La Niña events and above +0.5 for the El Niño events. 


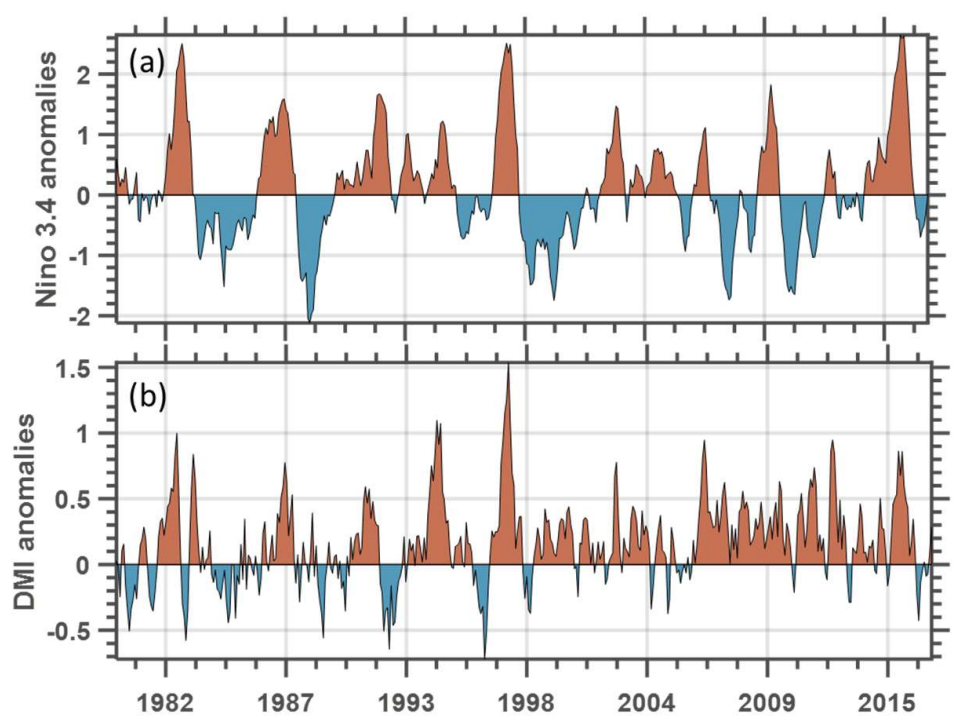

Figure 2. Standardized monthly Niño3.4 (a) and DMI (b) time series for the period from 1980 to 2017.

In Figure 2, both the El Niño events and positive DMI are shaded in red, whereas La Niña and negative DMI are indicated in blue. To identify the strength of the ENSO events the threshold is further broken down to weak (0.5-0.9 SST anomaly), moderate (1.0-1.4 anomaly) and strong ( $\geq 1.5$ anomaly) events. Figure 2a shows that the 2014-2016 El Niño was one of the strongest since the beginning of the record. Other notably strong El Niño occurrences were in 1982/1983, 1997/1998 and 2009/2010. On the other hand, there were many episodes of positive DMI, with one such event in 2014-2016, which seems to be in phase with the recent strong El Niño of 2014-2016.

Sixteen-year monthly mean NDVI data (2002-2017) averaged for the study area were used in this research. A composite of the index averaged for each year from 2002 to 2017 is shown in Figure 3 , in which the regions where there are greener colors indicate higher NDVI values, whereas the brownish colors indicate low NDVI values. These results show that there seems to be a direct influence of the ENSO in the vegetation of the HiP, especially during strong El Niño years. It is evident that during El Niño years, there was a decline in NDVI values especially in the southern and western parts of the study area. The evidence of greener regions in the eastern part of the reserve could presumably be because this area benefits from orographic lifting as it is situated in rising terrain (see Figure 1). The evidence of the influence of El Niño is more prominent during the strong El Niño years such as 2003, 2008 and the recent intense 2014-2016 drought period. 

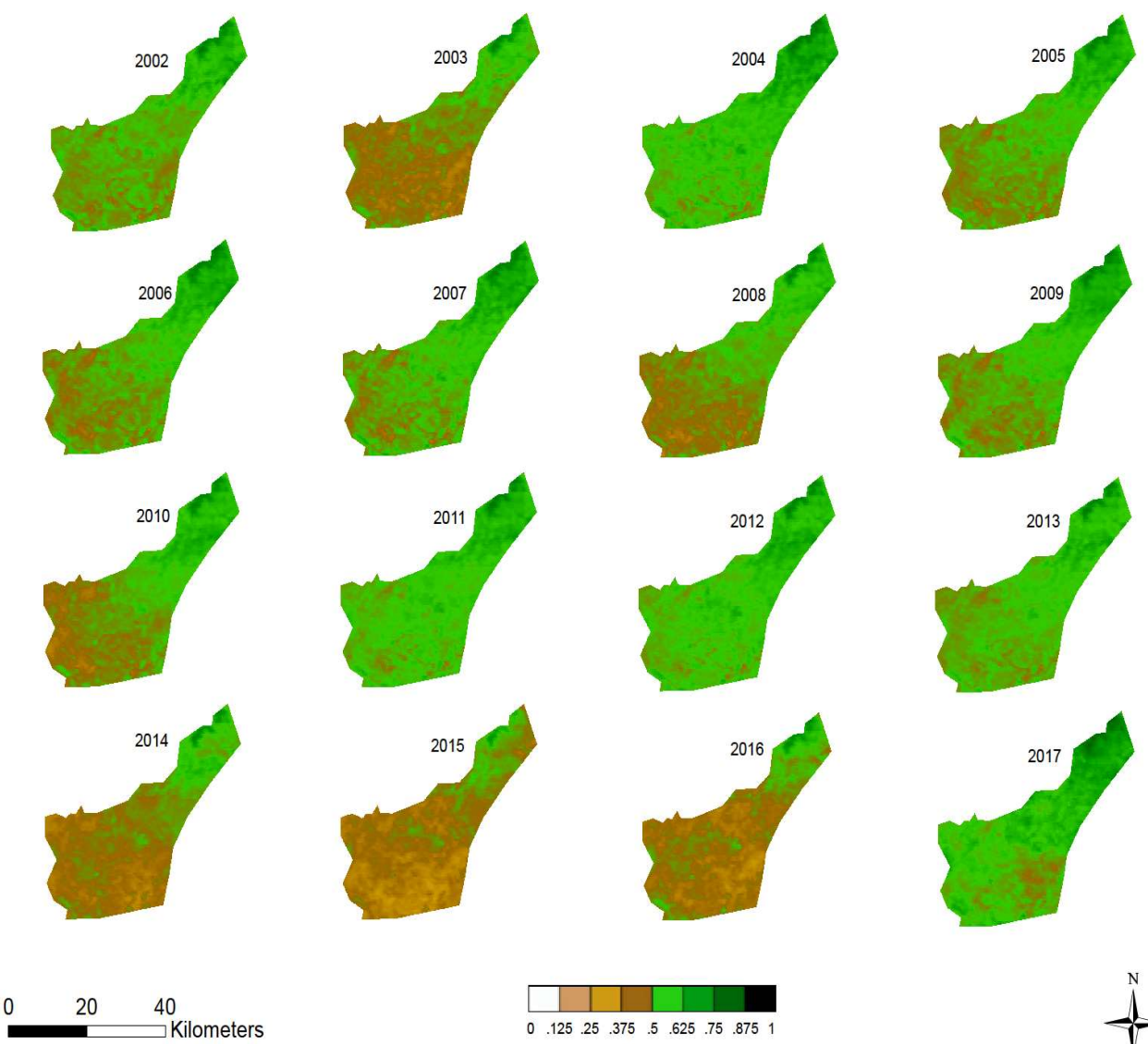

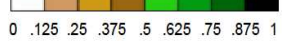

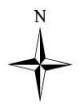

Figure 3. Spatiotemporal variability of NDVI at the HiP for the period from 2002 to 2017. The scale represents the range of NDVI values from 0 to 1.

Figure 4a shows the deseasonalized monthly averaged MODIS NDVI time series for HiP from 2002 to 2017. The continuous red line indicates the estimated trend and the dashed red lines show the $95 \%$ confidence levels. In general, NDVI values vary between 0.3 and 0.8 , with the dominance of the band between 0.5 and 0.65 (see Figure $4 \mathrm{~b}$ ). The NDVI trend estimate was calculated using the TheilSen method, which is outlined in a study by Wilcox [50]. Furthermore, Carslaw and Ropkins [51] also used this method to produce the TheilSen openair version 1.1-4 package function using Rproject version 3.1.2. Basically, this trend is represented by the percentage change, which is based on the NDVI values at the beginning and end months to express the mean slope. This trend $(T)$ is defined as:

$$
T\left(\% \cdot y r^{-1}\right)=100 \cdot\left(\frac{N D V I_{\text {end }}}{N D V I_{\text {start }}}-1\right) / N_{\text {years }}
$$

where NDVIend and NDVIstart are the mean NDVI values for the end and start dates, respectively, and $N_{y e a r s}$ is the total numbers of years in the corresponding time series. In regard to trend analyses, our results in Figure 4a show that the trend in the NDVI for the game reserve over the study period presented here was 0.0 per year, with the $95 \%$ confidence intervals in the trend ranging from 0.0 to 0.0 per year. The 0.0 per year trend estimate and the $95 \%$ confidence interval that range between 0 and 0 provide strong evidence that the NDVI trend was steady over the study period. This seems to be the case for southern Africa as other studies also indicate a steady trend for this region [10]. Remarkably, during the 2014-2016 period, a time that coincided with the recent intense El Niño, there 
was a sudden decrease in the NDVI values to the maximum minimum values of about 0.28. During this period, EVI values also decreased, to minimum values of about 0.11 (results not shown here).

(b)
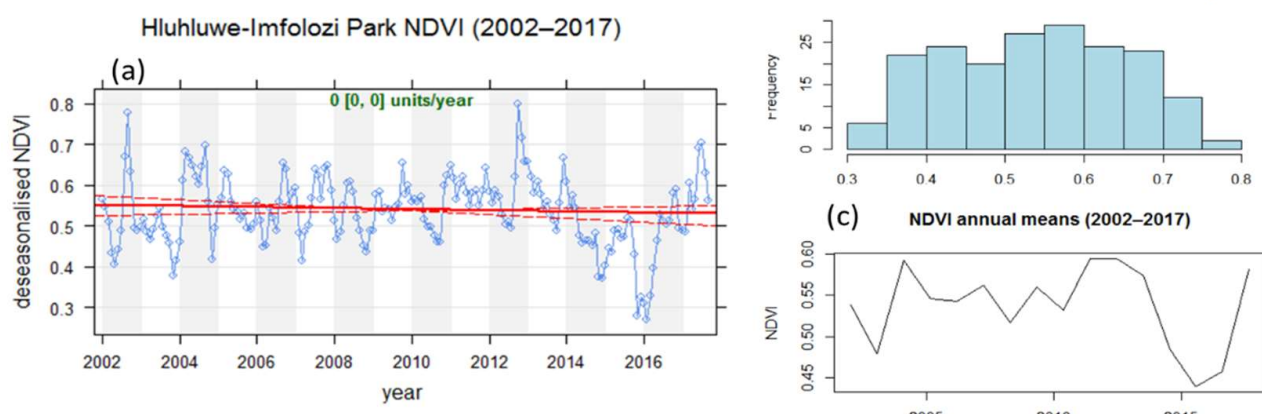

(c) NDVI annual means (2002-2017)

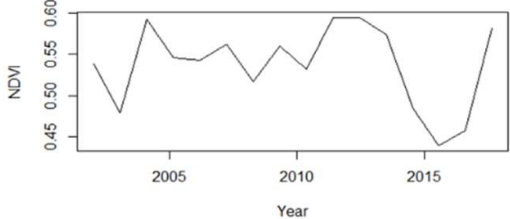

Figure 4. (a) Deseasonalized monthly mean NDVI time series for HiP. The continuous red line indicates the trend estimate and the dashed red lines show the $95 \%$ confidence interval for the trend based on resampling methods. (b) and (c) show the histogram and trend line of the NDVI monthly mean data and the monthly mean time series, respectively.

Mberego and Gwenzi [52] investigated temporal patterns of precipitation and vegetation variability over Zimbabwe during extreme dry and wet rainfall seasons using data covering the period 1981-2005. Their NDVI time series indicated a steady trend over this period; it seemed to be strongly affected by extremely dry conditions, which is consistent with the results presented here. The deseasonalized monthly mean NDVI time series in Figure 4a (blue line) indicates the possible response that corresponds to both dry and wet years, especially during the most recent strong El Niño events of 2003 and 2014-2016. Whereas Manatsa et al. [53] reported the 1991-1992 period as experiencing the most extreme drought, and Mberego and Gwenzi [52] the year 2002-2003 as the drought period with the most prolonged time of relatively low NDVI values, our observations indicate that 2014-2016 was the longest period with low NDVI values. Thus, 2014-2016 could be regarded as the most recent intense El Niño period, with the maximum effect on vegetation in the game reserve. The NDVI values dropped from a value just above 0.65 in November 2013 to 0.3 in November 2015. This is also verified by a much smoother representation of the NDVI in Figure 4c in which an obvious reduction in NDVI values is observed corresponding to the most recent strong El Niño. The influence of the El Niño of 2003 is also apparent in Figure 4c. Another significant feature is a strong peak, which reaches $\sim 0.8$ just after the Irina tropical storm, which occurred in early March 2012.

Figure 5 shows monthly mean time series values plotted together with their corresponding 12month running-mean smooth trend for NDVI (Figure 5a), EVI (Figure 5b), BAI (Figure 5c), maximum temperature (Figure 5d), and precipitation (Figure 5e). The smooth trend was extracted using the Breaks For Additive Season and Trend (BFAST) method, which is described by Verbesselt et al. [54, 55]. The BFAST method integrates the decomposition of time series seasonal, trend and remainder components of any satellite image time series, and can be applied to any other type of time series in the geosciences that deals with seasonal or non-seasonal time series. The period of the most recent intense drought (2014-2016) is indicated by the grey shaded box in each figure. In general, all the parameters show a seasonal cycle in terms of monthly means. 

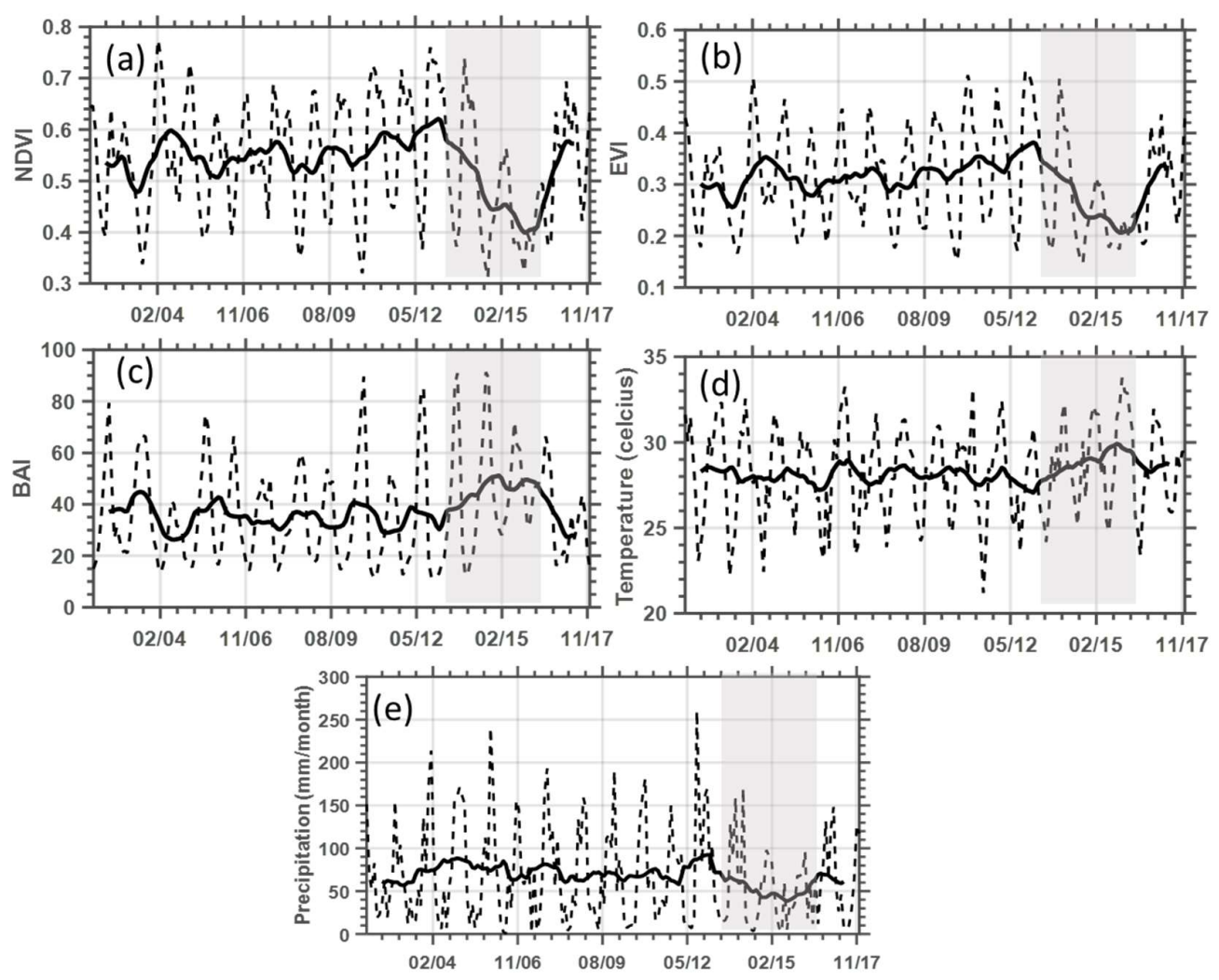

Figure 5. Monthly mean time series values of (a) NDVI, (b) EVI, (c) BAI, and MERRA-2 model maximum temperature (d) and precipitation (e)(dashed lines) and their respective 12-month smooth trends (continuous lines) for the period 2002 to 2017 for HiP.

There is expectedly a resemblance between the NDVI and EVI observations in both the monthly mean time series and the smooth trend, with a clear indication of the effect of the 2014-2016 drought period. This is consistent with a study by Xulu et al. [10], who investigated the response of commercial forestry to the recent strong and broad El Niño event just $60 \mathrm{~km}$ south of the HiP. They reported a significant decline in NDVI values, which corresponded to the 2014-2016 El Niño years [10]. Although the influence of the 2014-2016 El Niño in the game reserve seems to be the strongest, it follows the same pattern as that reported by Anyamba et al. [35] in their study of the influence of both El Niño and La Niña in the vegetation status over eastern and southern Africa. Considering the level of browning of vegetation demonstrated in Figure 3 for the years 2014-2016, it was necessary to consider the overall possible fire activity, given the relatively dry conditions. Figure $5 \mathrm{c}$ suggests that during the period of the intense drought of 2014-016 there was an increase in fire incidence as revealed by a rise in the BAI value to its maximum of approximately 50 .

The 12-month running mean smooth trends extracted using the BFAST method for NDVI, EVI and BAI plotted against anomalies of climatic forcers Niño3.4 and DMI are shown in Figure 6. This plot was constructed to investigate any possible 2-dimensional teleconnection between vegetation condition and the Niño3.4 and DMI climatic forcers, respectively. The panels on the left represent the vegetation indices and BAI versus Niño3.4, and those panels on the right show the vegetation indices versus DMI. Both the NDVI (Figure 6a) and EVI (Figure 6b) values show a fairly steady pattern for most parts of the time series, which vary between NDVI values of 0.50 and 0.60 , and between EVI values of 0.28 and 0.34 . However, both the NDVI and EVI values seem to be enhanced by the extreme amount of rainfall that was brought by the tropical cyclone Irina during early 2012 in the eastern part of southern Africa. In that year, NDVI values increased to their maximum of approximately 0.62 , whereas the more sensitive EVI index reached its maximum of approximately 0.38 . The strong peaks that were observed during 2004 in the NDVI and EVI time series correspond to the greening of vegetation in the HiP, which was produced by the heavy rainfall that was brought by tropical cyclone 
Elite in January 2004 [56]. NDVI values were observed to decrease sharply from late 2013 until they reached their minimum of approximately 0.40 in 2015 before beginning to recover to normal average conditions in 2017. This pattern is also depicted in the EVI time series, and is directly linked to the stronger and more extensive 2014-2016 El Niño event. Similar results were also presented in the study by Xulu et al. [10], who investigated the influence of recent drought on forest plantations in Zululand. The notable browning observed in Figure 3 for years 2014, 2015 and 2016, which was also revealed by the NDVI and EVI time series (Figure 5), seems to represent favourable conditions for biomass burning in the game reserve. This is revealed by the unprecedented sudden increase in BAI to its greatest maximum of approximately 50, which coincides with the enhancement of Niño3.4 during 2014-2016 (Figure 6e).

The DMI was highly variable compared to the Niño3.4 climatic forcers throughout the study period, with several distinctive positive DMI values that reached a maximum of just below 1.0. Remarkably, there is a strong peak that extends up to approximately 0.8 during the period band corresponding to 2014-2016 that coincided with the decline in NDVI and EVI and the increase of the ENSO and BAI time series. We note here that the widespread browning observed during the 20142016 drought period could have been accelerated by the fact that the climatic forcers, which are known to influence the south-eastern part of southern Africa, may have been in phase during this period. This, of course, needs further investigation; and is discussed below.
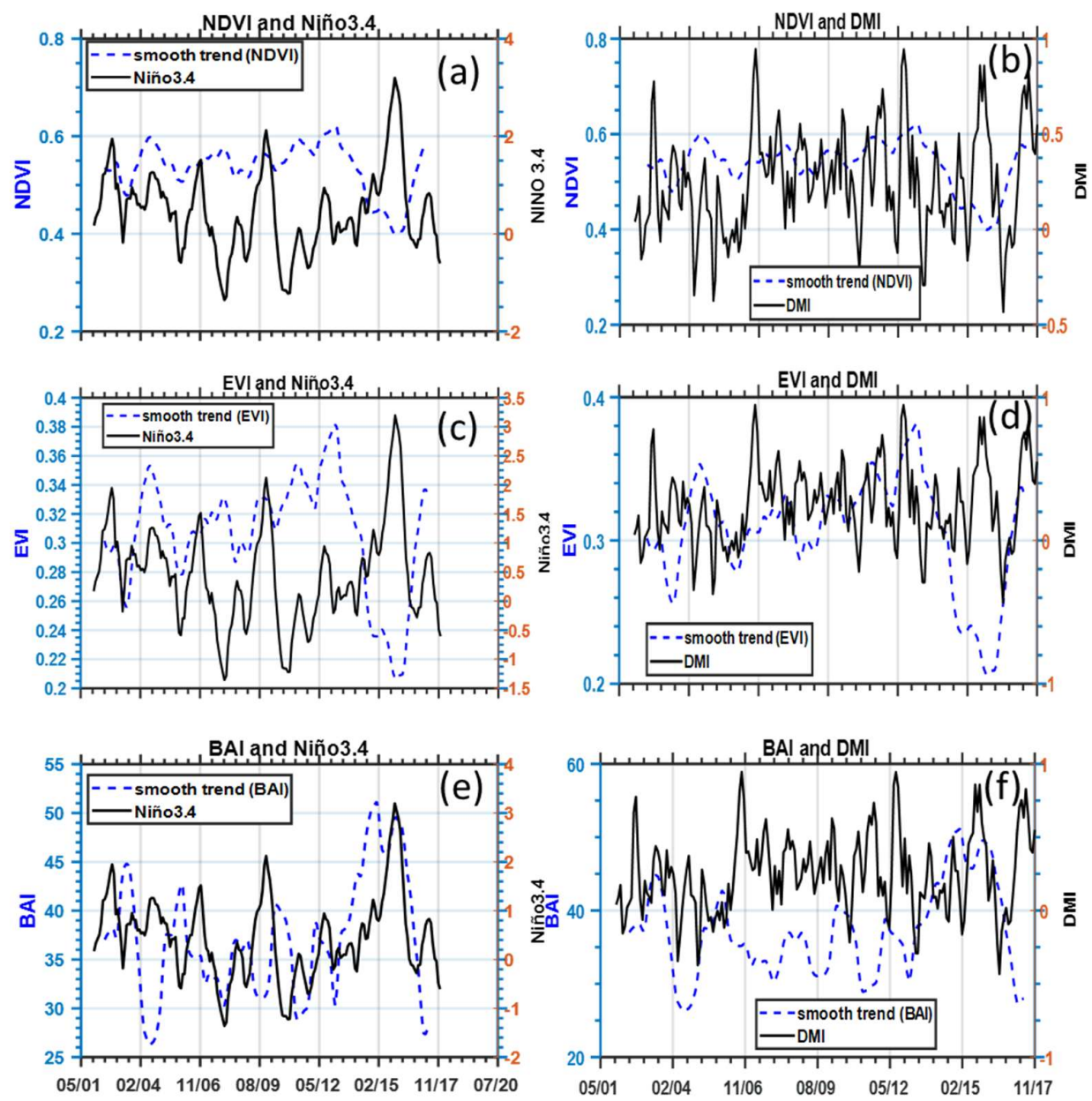

Figure 6. (a, b) NDVI, (c, d) EVI and (e, f) BAI (blue dashed line) 12-month smooth trends versus Niño3.4 (left panels) and DMI (right panels) for the period from 2002 to 2017 for the HiP. 


\subsection{Correlations Statistics and Mann-Kendall Test}

Figure 7 shows the interannual variability of the Pearson linear correlation between the HiP NDVI values and parameters such as Niño3.4, DMI, maximum temperature, precipitation, and BAI, for the period from 2002 to 2017. In this figure, factors such as precipitation, maximum temperature and DMI seem to be positively correlated with the NDVI, with maximum temperature and rainfall reaching values above 0.5 in the years 2002 and 2006, respectively. As expected, the Niño3.4 index versus NDVI correlation is dominated by negative values that are much more prominent in periods corresponding to El Niño years. This is consistent with previous studies such as those of Xulu et al. $[10,35]$, who reported a significant influence of ENSO on the vegetation of southern Africa, especially the north-eastern part. Moreover, a salient observation is that the greatest minimum correlation recorded was in 2015, a year with a particularly strong El Niño. The negative correlation between DMI and NDVI also seems to be greater during the recent intense drought period, which could indicate that Niño3.4 and DMI were in phase during this time. The correlation between NDVI and the BAI is expected to be strongly negative as greening is not conducive to biomass burning. However, the results presented in Figure 7 indicate that there was a sudden increase of correlation between NDVI and BAI in 2015 before it returned to its average position in 2016 and 2017. Overall, the interannual variation of almost all the study parameters indicates a noticeable change during El Niño events in the years 2003 and 2008 and was especially prominent during the 2014-2016 period.

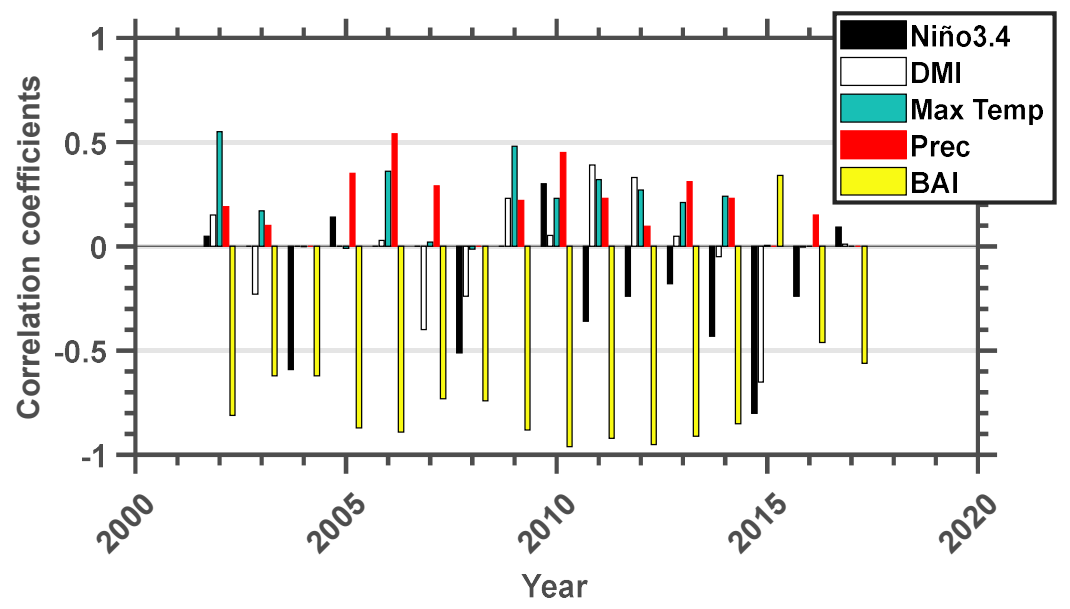

Figure 7. Linear correlations between NDVI and the parameters Niño3.4, DMI, maximum temperature (Max Temp), precipitation (Prec) and BAI for each year in the period from 2002 to 2017.

While the Pearson linear regression is useful to investigate the yearly variability of the relationship between the climatic variables used here and NDVI, the Pearson correlation for the whole record was also derived. Figure 8 shows the heatmap which summarizes the linear relationships between all the parameters monitored in this study. Of significance is the strong negative correlation between the NDVI and BAI, which is not surprising because greener vegetation reduces chances of biomass burning, while the possibility of the satellite detecting the charcoal signal from burnt vegetation during dry conditions is high. On the other hand, a noteworthy positive $(r=$ $0.43)$ and negative $(r=-0.27)$ correlation between NDVI and precipitation and Niño3.4, respectively, was observed. The correlation between NDVI and temperature was less $(r=0.19)$ than that of precipitation and Niño3.4. Although Figure 2 indicate some cases where a strong Niño3.4 peak is in phase with DMI peaks, the noteworthy correlation of $r=0.28$ between these two climatic indices seems to reaffirm this. 


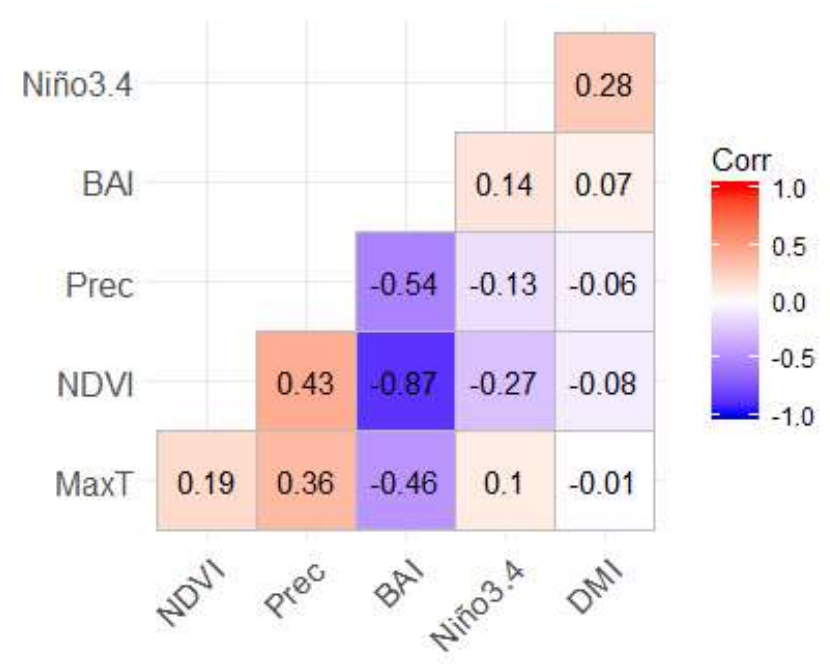

Figure 8. Heatmap of Pearson correlation coefficients for NDVI, precipitation (Prec), maximum temperature (MaxT), BAI, Niño3.4 and DMI.

A comprehensive summary of the MLR analysis statistics encompassing NDVI, temperature, precipitation, Niño3.4, and DMI is shown in Table 1. It should be mentioned that the temperature, precipitation and Niño3.4 parameters were chosen because of their well-known possible influence on NDVI variability, whereas DMI was selected to test the possibility of such influence. The results reveal a statistically significant relationship between NDVI and precipitation and Niño3.4, with $p$ values of $2.0 \times 10^{-7}$ and $8.4 \times 10^{-4}$, respectively. In contrast, the linear correlation between both temperature and DMI was observed to be not significant when considering the whole time series even though results presented in Figure 7 indicate the clear influence of these factors during the 20142016 period. A positive significant correlation between precipitation and NDVI, which is also represented as in Figure 8, indicates that precipitation may be more influential with regard to NDVI variability in the study area than temperature. The significant but negative correlation between Niño3.4 and NDVI confirms the notion that ENSO variability plays a role in the climatic conditions of southern Africa [35,52].

Table 1. Output of the MLR model in which NDVI is a dependent variable and temperature, precipitation, Niño3.4 and DMI are independent variables.

\begin{tabular}{crrrrr}
\hline Variable & Estimate & Std. Error & t-value & p-value & Sig \\
\hline (Intercept) & 0.4039074 & 0.0809350 & 4.9910000 & 0.0000014 & $* * *$ \\
Maximum temperature & 0.0033390 & 0.0029649 & 1.1260000 & 0.2615530 & \\
Precipitation & 0.0007725 & 0.0001434 & 5.3860000 & 0.0000002 & $* * *$ \\
Niño3.4 & -0.0304511 & 0.0089747 & -3.3930000 & 0.0008460 & $* * *$ \\
DMI & 0.0041454 & 0.0275409 & 0.1510000 & 0.8805210 & \\
\hline
\end{tabular}

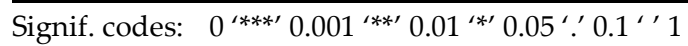

In order to verify the output of the Theilsen method used above, this study also invoked the Mann-Kendall trend test. The main advantage of this technique is that it provides a non-parametric test that does not require the data to be normally distributed and also it is not dependent on the magnitude of data. Furthermore, this non-parametric test method has low sensitivity to abrupt breaks in heterogeneous time series [57]. The Mann-Kendall test model was applied to the NDVI data, with results shown in Figure 9. In summary, the z-score and p-value for the entire NDVI time series period (2002-2017) were found to be -1.22 and 0.224 , respectively. Both the $z$-score and the $p$-value seem to indicate that there was no significant trend in the NDVI data. But there was an indication of an 
insignificant downward trend (negative $z$-score) presumably due to the sudden reduction of the NDVI values which coincided with the 2014-2016 drought. In order to investigate the influence of drought conditions in the study area using the Mann-Kendall method, it was necessary to calculate the inter-annual variation of Mann-Kendall $z$-scores.

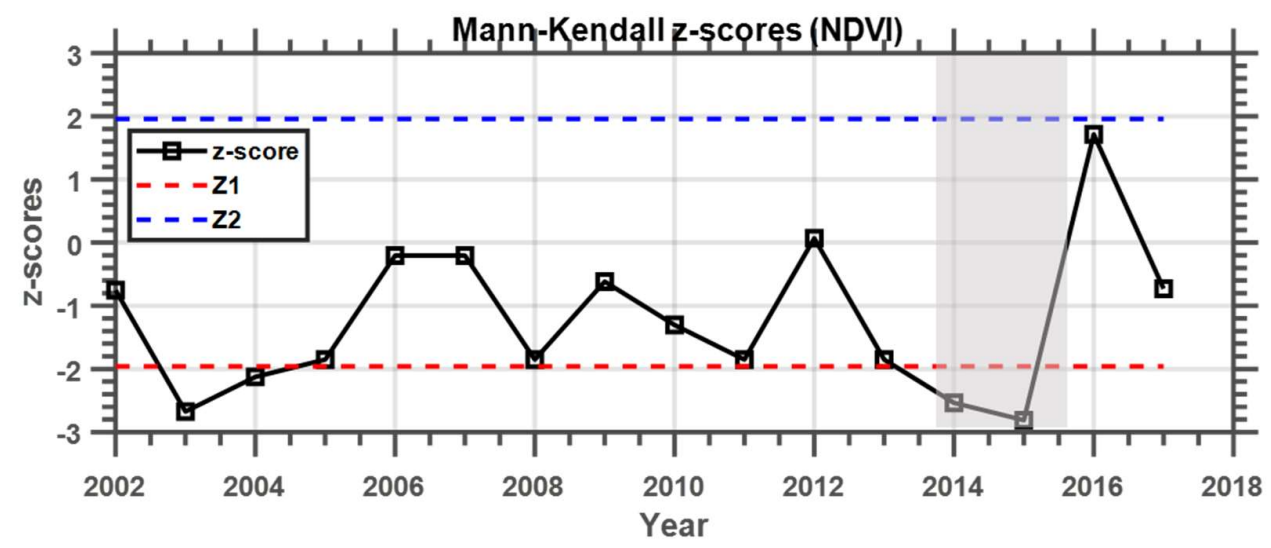

Figure 9. Inter-annual variation of Mann-Kendall $z$-scores $(\alpha=0.05, Z 1=-1.96, Z 2=1.96)$ for the HiP from 2002 to 2017.

Figure 9 shows the Mann-Kendall $z$-scores based on the 16 years of monthly average NDVI data for the game reserve. In general, it is expected that vegetation will respond to climate fluctuating conditions, and this is clearly depicted by significantly negative $z$-scores (less than $Z 1=-1.96$ ) during strong El Niño events (e.g. in 2003 and 2014/2015). The significant downward trend observed between 2014 to 2015 is the strongest such downward trend in the history of the MODIS NDVI data used in this study; it demonstrates a clear response of the vegetation of the reserve to the strong El Niño event of 2014-2016. A similar analysis and results comparable with those presented here was reported by Hou et al. [17] in their study on the inter-annual variability in growing-season NDVI and its correlation with climate variables in the south-western Karst region of China.

\subsection{Wavelet analyses}

In order to analyze localized variation of the spectral power within the time series, wavelet analyses, the most common tool for this purpose, were also conducted. As mentioned earlier, the wavelet method assists by decomposing a time series into time-frequency space, which makes it possible to determine the dominant modes of variability and how they vary in time. Figure 10 shows the normalized wavelet power spectra for the monthly mean NDVI, precipitation, DMI, Niño.3.4 and maximum temperature data recorded for the game reserve. The results of the EVI wavelet analyses are not shown here because they are nearly identical to those for NDVI. In Figure 10, blue indicates low wavelet power and yellow represents areas of high wavelet power. The wavelet power area that is considered in what follows is that which is within the cone-of-influence which is indicated by the solid u shaped line.

The NDVI of the HiP seems to follow the distinctive pattern of seasonality of precipitation in the north-eastern part of South Africa, which experiences rainfall during the summer period (DecemberFebruary). This is confirmed by a statistically significant peak observed at around the12-month cycle (see Figure 10a), which seems to correspond with that of precipitation (Figure 10b) and of maximum temperature (Figure 10e) throughout the year. This is plausible because wet seasons (summer in this case) lead to increased soil moisture and also create conditions of low evapotranspiration and thus accelerate the greening process in the game reserve. Similarities in the wavelet power spectra of temperature and especially precipitation to that of NDVI therefore suggest that the vegetation health in the HiP was primarily driven by precipitation. This is not surprising considering the strong annual- 
mean correlation between precipitation and NDVI presented in Figure 7. It should also be noted that the NDVI wavelet power spectra have significant peaks showing the presence of the semi-annual oscillation (6 months), which is observed during the distinctive period from 2006/2007 to 2011/2012. The results of the NDVI wavelet spectral analysis presented here are remarkably similar to the findings of Azzali and Menenti [12], who used a Fourier transform-based technique and reported a substantial seasonal change in NDVI for southern Africa. The high and significant power of a period of 3-4 months that is observed in both the periods 2012/2013 and 2015/2016, is perhaps related to cyclone Irina in early 2012 and the most recent intense drought of 2014-2016. The wavelet power spectra of the DMI indicate significant power peak of distinctive periods in the 3-20 months band primarily during the period between 2008 and 2013. On the other hand, the Niño3.4 power spectra exhibit significant power peaks in the 8-32 months band throughout the study period. It should be noted, however, that this frequency occurrence of peaks observed in the Niño3.4 wavelet spectra is similar to that reported in the studies of Torrance and Compo [45] and also of Jevrejeva et al. [46], who used a much longer time series of Niño3.4.
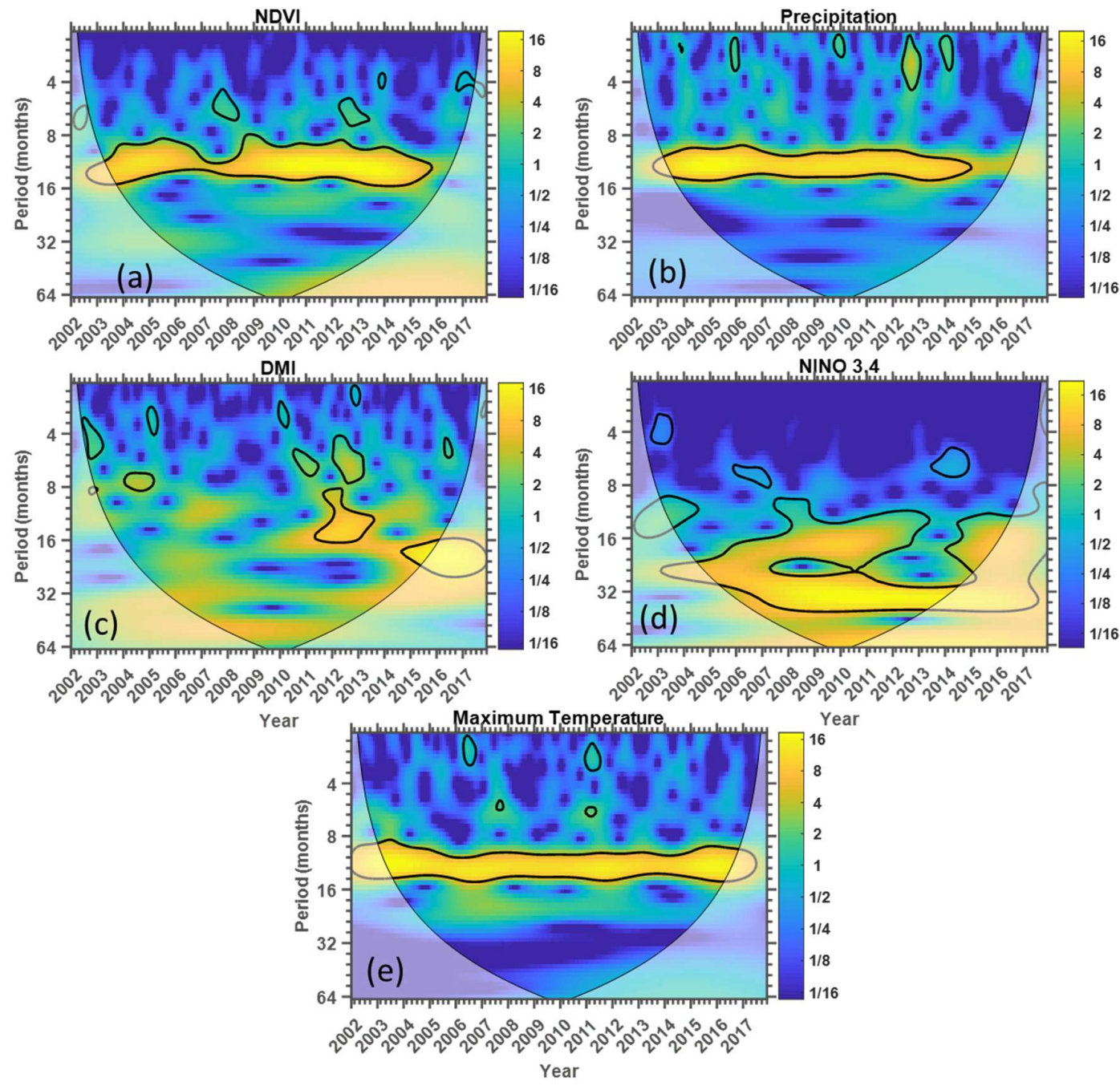

Figure 10. Normalized wavelet power spectra of monthly mean (a) NDVI, (b) precipitation, (c) DMI, (d) Niño3.4 and (e) maximum temperature plotted for the period from 2002 to 2017. The black lines which encircles yellowish colors indicate the areas of significance at the $95 \%$ confidence level using the red noise model. 
The coherence between DMI, maximum temperature, precipitation, Niño3.4 and NDVI was investigated to determine whether the NDVI significant wavelet spectra peaks observed at a given time correspond with those observed for the other parameters. Furthermore, the phase relationship between NDVI and the other parameters was calculated and superimposed graphically in Figure 11. The phase relationship is represented by arrows, where two cross-wavelet parameters are in phase if the arrows point to the right, anti-phase if the arrows point to the left, and leading or lagging if the arrows point upwards or downwards, respectively. More details about these calculations can be found in studies by Jevrejeva et al. [46, 47] and later by Schulte et al. [49].
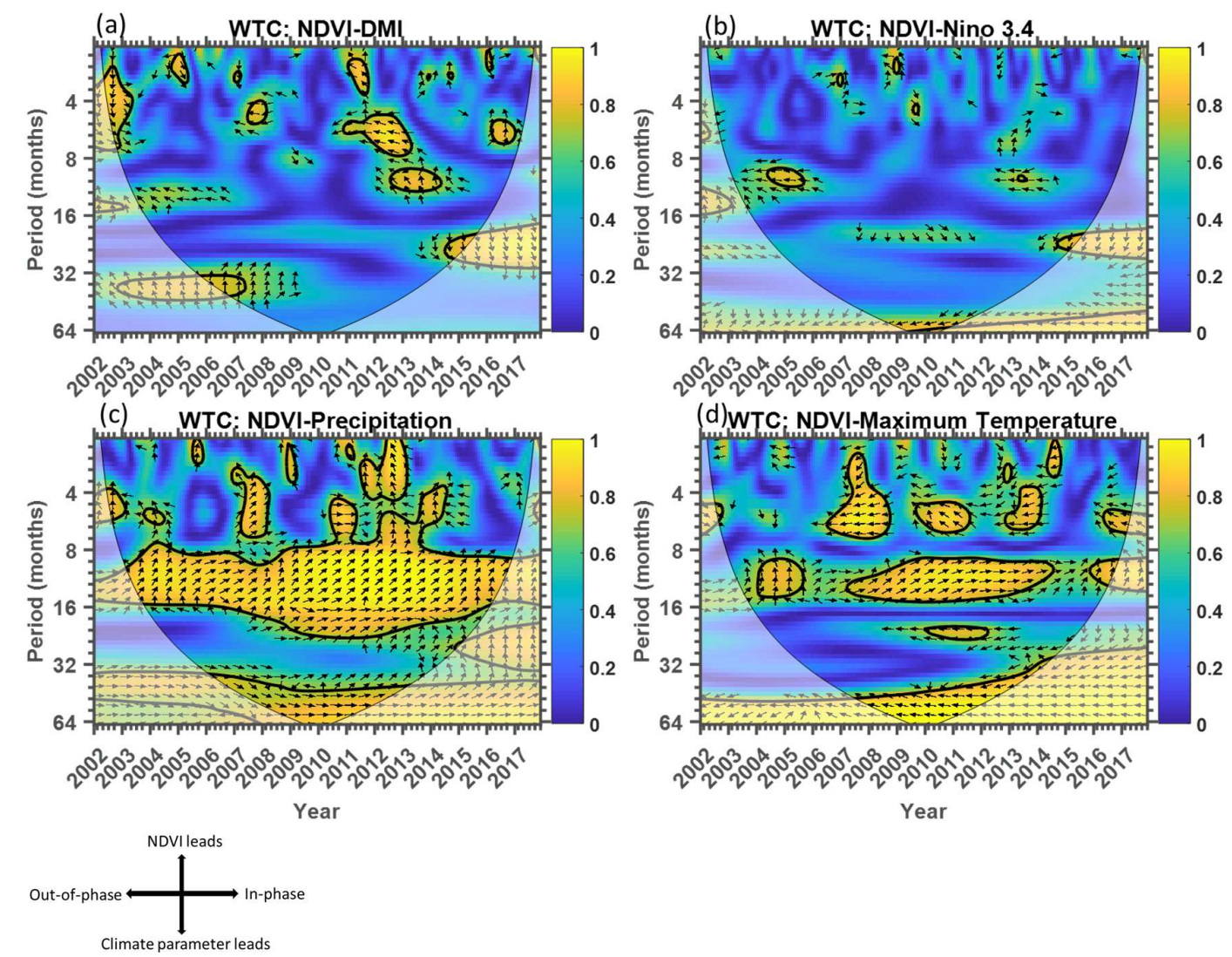

Figure 11. Squared cross-wavelet power spectra between NDVI and (a) DMI, (b) maximum temperature, (c) precipitation and (d) Niño3.4. The continuous black lines demarcate the areas of significance at the $95 \%$ confidence level using the red noise model. The arrows are vectors indicating the phase difference between the cross-wavelet parameters (see the legend in the bottom left corner).

The local wavelet coherence spectra together with their distinctive cross-spectra phase for NDVI-DMI, NDVI-Niño3.4, NDVI-precipitation and NDVI-maximum temperature are shown in Figure 11. In general, all the wavelet coherence spectra indicate that DMI, Niño3.4, precipitation and temperature have some sort of coherence with the HiP NDVI in a variety of both periods and timescales. However, it should be mentioned that because statistically the significant correlation between any two variables being investigated could occur by chance, significant commonality in a wavelet coherence spectra analysis does not necessarily imply interconnection. Moreover, there is a possibility of smaller areas of wavelet coherence occurring by chance, which would not indicate interconnection, whereas larger areas of significance are improbable due to chance. For this reason further investigation is required in regard to possible teleconnection between any two-time series. 
The wavelet coherence between NDVI and DMI is observed to delineate some areas that have high significant power at periods of 2-16 months. It is also important to mention that there are significant peaks which are within the cone of influence at the period band 32-48 months during years 2005-2007? and 2013/2014, respectively. The cross-wavelet phase during the years 2013/2014 indicates that the DMI was leading the NDVI. Torrance and Compo [45] investigated the periodicities present in a much longer time series (1871-1996) of Niño3.4 using Morlet wavelets and reported the domination of periods greater than 12 months, while some smaller episodes of shorter periods were also present in their spectra. In this study, the wavelet coherence between NDVI and Niño3.4 indicates smaller or no areas of high power significance, which is understandable because the 16-year monthly mean NDVI time series is dominated by periodicities less than 16 months (Figure 10a) whereas the Niño3.4 wavelet spectra are dominated by periodicities greater than 12 months. Remarkably, there is a significant power at a period band of 22-27 months from 2014 to 2017 with cross-spectra phase pointing at leading position (NDVI leads), which indicates that the recent strong El Niño event may have influenced the response of NDVI illustrated in Figure 4a. This significant peak seems to be similar to that observed in the NDVI wavelet coherence spectra, indicating it is possible that the DMI and Niño3.4 time series were in phase during this period. If so, their joint effect could have maximized the browning observed in years 2014-2016. The wavelet coherence between NDVI and both the precipitation and temperature records indicates high significant power during most parts of the study record, with the precipitation spectra phase (Figure 11c) being dominated by leading NDVI phase during the early part of the record. The phase relationship changes to an inphase direction in the middle of the record, before it returns to the leading NDVI phase during the latter part of the record for the period band 8-18 months. This pattern is also observed in the distinctive periods which are less than 8 months especially for the period 2006-2013. The NDVI and temperature wavelet coherence spectra delineate distinctive high power significance with an antiphase relationship in a 2-8 months band for years 2006-2014. Apart from the two distinctive period bands of 2004-2006 and 2015-2017 of high significant power during which the NDVI time series lead the temperature time series during the period band 9-14 months, the annual cycle is dominated by the in-phase relationship; both scenarios also indicate the a possible teleconnection between the two time series.

Overall, factors such as DMI, Niño3.4, precipitation and temperature are shown to influence NDVI at different distinctive periods and time scales. During La Niña years, the relationship between NDVI and precipitation and temperature seems to not indicate any alarming patterns. However, during strong El Niño years (especially broad and strong ones as in 2014-2016), intense drought occurs. This condition is associated with less humidity and cloud cover, which allows for more solar radiation reaching the ground and accelerated evapotranspiration, which impede photosynthesis.

\section{Conclusions}

Our results indicate that drought stress reaction patterns of vegetation within HiP provide temporal responses to climate variability, suggesting a strong causal influence. Both the NDVI and EVI values, averaged over the study area, decreased suddenly during 2014-2016 to their greatest minima of approximately 0.28 and 0.11 , respectively, in 2016. The linear relationship (both Pearson and MLR) between climatic indices and NDVI indicated that precipitation and ENSO play a significant role in the variability of vegetation health. The Pearson correlation $r$ and MLR p-value for precipitation and ENSO were found to be 0.45 and $2.0 \times 10^{-7}$, and 0.27 and $8.4 \times 10^{-4}$, respectively. While some studies [17] reported temperature as the main meteorological parameter that influences vegetation, in our study we conclude that the influence of precipitation on vegetation was more significant. Moreover, terrain appears to have additional influence on the state of vegetation in the reserve. For example, the lower NDVI values corresponded with 2014-2016 drought period, particularly in the south-western (flat) part of the reserve, whereas the eastern parts (hilly) seem to have benefited from orographic precipitation which promoted vegetation growth. Terrain is also assumed to restrict wildlife grazing in hilly parts of the reserve where stable NDVI are noticeable, placing more burden in flat areas that are accessible to most grazers. 
The Mann-Kendall trend significance test of the HiP time series revealed a decreasing pattern during the extreme drought periods of 2003 and 2015-2016, with the lowest minimum during 2015. This study has also demonstrated how the wavelet coherence signal processing technique can serve in identifying periodicities in NDVI time series, and can also help demonstrate temporal response of vegetation status to environmental disturbances. The wavelet coherence power spectra indicate the strong influence of precipitation on NDVI variation, which is also explained by the wavelet power spectra of NDVI that seem to follow that of precipitation. While the El Niño of 2014-2016 was both extended and strong, it is possible that its influence in the study area was also supported by a corresponding positive DMI peak which took place at the same time with the with the 2014-2016 El Niño period. It is, therefore, desirable to use the wavelet coherence technique and other methods to investigate the phase relationship between ENSO and DMI for determining the corresponding influence of rainfall in the north-eastern part of South Africa.

Finally, we conclude that the recent intense drought of 2014-2016 influenced the spatiotemporal pattern of vegetation condition in the HiP. This hold more implications for tourism potential of the $\mathrm{HiP}$ as attractive grazers such as white rhinos and buffalos were reportedly affected by this event [11]. The results portend that the freely GEE-archived satellite data is a capable tool for monitoring drought with a high temporal resolution across game reserves located in drought prone areas of South Africa and other parts of the world.

Author Contributions: N.M. and S.X. designed the research. N.M. performed data analyses, visualization, and interpretation of results. N.M. and S.X. wrote the paper.

Funding: This research is funded by the National Research Foundation of South Africa and the University of Zululand.

Acknowledgments: The authors would like to thank all personnel involved in the development of the Google Earth Engine system and climate engine. We also thank the providers of the important public data set in the Google Earth Engine, in particular, NASA, USGS, NOAA, EC/ESA, and MERRA-2 model developers.

Conflicts of Interest: The authors declare no conflict of interest. 


\section{Appendix A}

Here we show the Google Earth Engine interactive development environment. The dark green area indicates the location of the Hluhluwe-iMfolozi Park in north-eastern South Africa. The NDVI time series, which is averaged for the study area, is shown in the console part of the GEE interactive development environment.

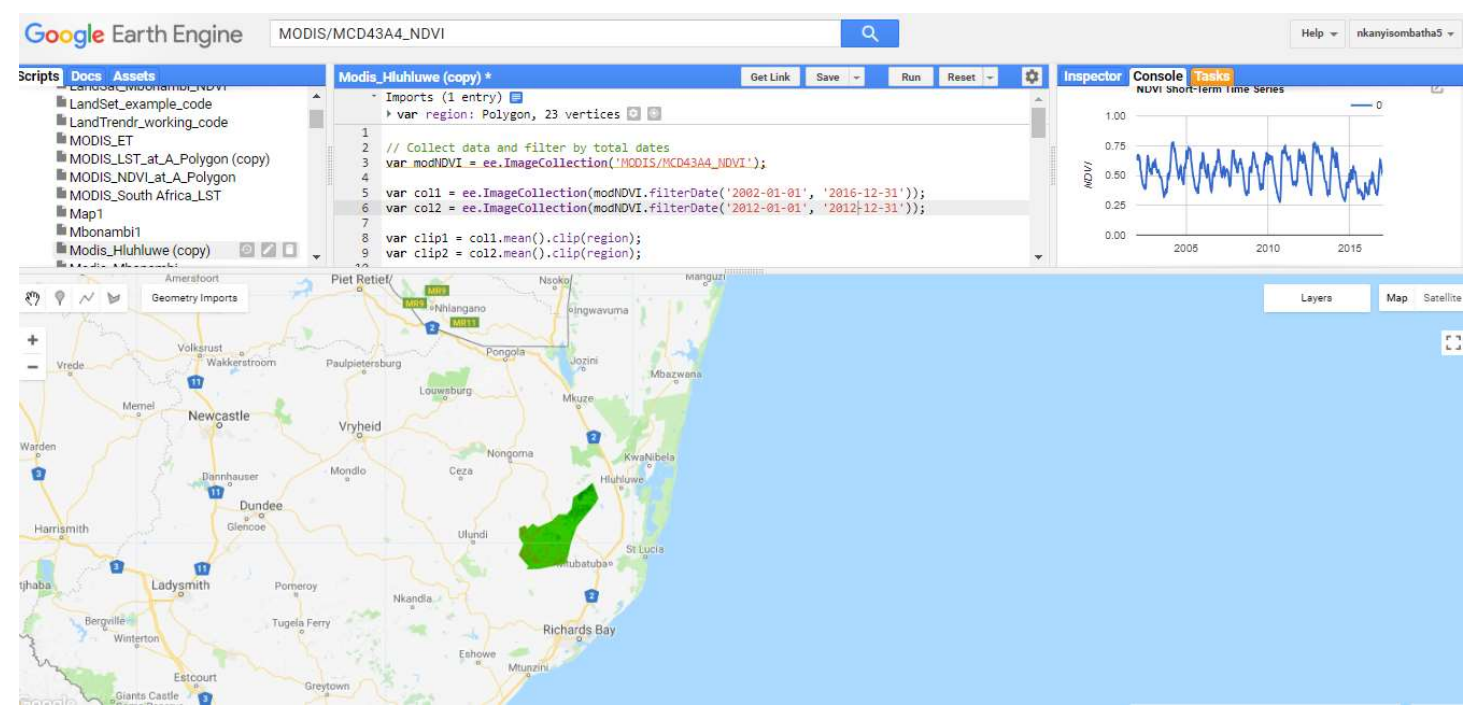

\section{References}

1. Stolton, S.; Dudley, N.; Avcıoğlu Çokçalışkan, B.; Hunter, D.; Ivanić, K.Z.; Kanga, E.; Kettunen, M.; Kumagai, Y.; Maxted, N.; Senior, J.; Wong, M. Values and benefits of protected areas. In: Worboys, G.L, Lockwood, M, Kothari, A, Feary, S, Pulsford, I (Eds.) Protected area governance and management; ANU Press: Canberra, Australia, 2015; pp. 145-168.

2. Kettunen, M.; ten Brink, P. Social and economic benefits of protected areas: An assessment guide; Routledge: Abingdon, United Kingdom, 2013.

3. White, R.P.; Murray, S.; Rohweder, M.; Prince, S.D; Thompson, K.M. Grassland ecosystems; World Resources Institute: Washington DC, USA, 2000.

4. Sruthi, S.; Aslam, M.M. Agricultural drought analysis using the NDVI and land surface temperature data; a case study of Raichur district. Aquat. Procedia. 2015, 4, 1258-1264.

5. Wilhite, D.A.; Svoboda, M.D.; Hayes, M.J. Understanding the complex impacts of drought: A key to enhancing drought mitigation and preparedness. Water Resour. Manag. 2007, 21, 763-774.

6. Myhre, G.; Shindell, D.; Bréon, F.M.; Collins, W.; Fuglestvedt, J.; Huang, J.; Koch, D.; Lamarque, J.F.; Lee, D.; Mendoza, B.; Nakajima, T. Climate change 2013: The physical science basis. Contribution of working group I to the fifth assessment report of the Intergovernmental Panel on Climate Change In Tignor, K., Allen, M., Boschung, SK, Nauels, J., Xia, Y.; Bex, V.; Midgley, PM Cambridge University Press Cambridge; United Kingdom and New York, USA, 2013.

7. Clark, P.U.; Shakun, J.D.; Marcott, S.A.; Mix, A.C.; Eby, M.; Kulp, S.; Levermann, A., Milne, G.A.; Pfister, P.L.; Santer, B.D.; Schrag, D.P. Consequences of twenty-first-century policy for multi-millennial climate and sea-level change. Nat Clim Chang. 2016, 6, 360.

8. Duncan, J.M.; Biggs, E.M. Assessing the accuracy and applied use of satellite-derived precipitation estimates over Nepal. Appl. Geogr. 2012, 34, 626-638.

9. Dube, L.; Jury, M. The nature of climate variability and impacts of drought over KwaZulu-Natal, South Africa. S. Afr. Geogr. J. 2000, 82, 44-53.

10. Xulu, S.; Peerbhay, K.; Gebreslasie, M.; Ismail, R. Drought influence on forest plantations in Zululand, South Africa, using MODIS time series and climate data. Forests. 2018. 9, 528, doi:10.3390/f9090528.

11. Whateley, A. The impact of drought in the Hluhluwe imfolozi Park (HiP) South Africa. 2017; Available online: http://theconservationimperative.com/?p=235 (accessed on 10 June 2018). 
12. Azzali, S.; Menenti, M. Mapping vegetation-soil-climate complexes in southern Africa using temporal Fourier analysis of NOAA-AVHRR NDVI data. Int. J. Remote Sens. 2000, 21, 973-996.

13. Hassan, M.H; Hutchinson, C. Natural resource and environmental information for decision making;The World Bank: Washington DC, USA, 1992.

14. Xie, Y.; Sha, Z.; Yu, M. Remote sensing imagery in vegetation mapping: A review. J. Plant Ecol. 2008, 1, 923.

15. Deshayes, M.; Guyon, D.; Jeanjean, H.; Stach, N., Jolly, A.; Hagolle, O. The contribution of remote sensing to the assessment of drought effects in forest ecosystems. Ann. For. Sci. 2006, 63, 579-595.

16. Fensholt, R.; Rasmussen, K.; Nielsen, T.T; Mbow, C. Evaluation of earth observation based long term vegetation trends-intercomparing NDVI time series trend analysis consistency of Sahel from AVHRR GIMMS, Terra MODIS and SPOT VGT data. Remote Sens. Environ. 2009, 113, 1886-1898.

17. Hou, W.; Gao, J.; Wu, S; Dai, E. Interannual variations in growing-season NDVI and its correlation with climate variables in the southwestern karst region of China. Remote Sens. 2015, 7, 11105-11124.

18. Xu, C.; Hantson, S.; Holmgren, M.; Nes, E.H.; Staal, A.; Scheffer, M. Remotely sensed canopy height reveals three pantropical ecosystem states. Ecology. 2016, 97, 2518-2521.

19. Tucker, C.J. Red and photographic infrared linear combinations for monitoring vegetation. Remote Sens. Environ.1979, 8, 127-150.

20. Poveda, G.; Salazar, L.F. Annual and interannual (ENSO) variability of spatial scaling properties of a vegetation index (NDVI) in Amazonia. Remote Sens Environ. 2004, 93,391-401.

21. Wang, J.; Rich, P.M.; Price, K.P.; Kettle, W.D. Relations between NDVI and tree productivity in the central Great Plains. Int. J. Remote Sens. 2004, 25, 3127-3138.

22. Forkel, M.; Carvalhais, N.; Verbesselt, J.; Mahecha, M.D.; Neigh, C.S; Reichstein, M. Trend change detection in NDVI time series: Effects of inter-annual variability and methodology. Remote Sens. 2013, 5, 2113-2144.

23. Liu, S.; Zhang, Y.; Cheng, F.; Hou, X; Zhao, S. Response of grassland degradation to drought at different time-scales in Qinghai Province: Spatio-temporal characteristics, correlation, and implications. Remote Sens. 2017, 9, 1329.

24. Jiang, L.; Shang, S.; Yang, Y.; Guan, H. Mapping interannual variability of maize cover in a large irrigation district using a vegetation index-phenological index classifier. Comput. Electron. Agric. 2016, 123, 351-361.

25. Cui, Y.P.; Liu, J.Y.; Hu, Y.F.; Kuang, W.H; Xie, Z.L. An analysis of temporal evolution of NDVI in various vegetation-climate regions in Inner Mongolia, China. Procedia Environ. Sci. 2012, 13, 1989-1996.

26. Huang, F.; Mo, X.; Lin, Z; Hu, S. Dynamics and responses of vegetation to climatic variations in ZiyaDaqing basins, China. Chinese Geogr. Sci. 2016, 26, 478-494.

27. Bond, W.J; Archibald, S. Confronting complexity: Fire policy choices in South African savanna parks. Int. J. Wildland Fire. 2003, 12, 381-389.

28. Nsukwini, S.; Bob, U. The socio-economic impacts of ecotourism in rural areas: A case study of Nompondo and the Hluhluwe-iMfolozi Park (HiP). A. J. Hosp. Tour. Leisure. 2016, 5, 1-15.

29. Boundja, R.P.; Midgley, J.J. Patterns of elephant impact on woody plants in the Hluhluwe-imfolozi park, Kwazulu-Natal, South Africa. Afr. J. Ecol. 2010, 48, 206-214.

30. Trinkel, M.; Ferguson, N.; Reid, A.; Reid, C.; Somers, M.; Turelli, L.; Graf, J.; Szykman, M.; Cooper, D.; Haverman, P.; Kastberger, G. Translocating lions into an inbred lion population in the Hluhluwe-iMfolozi Park, South Africa. Anim. Conserv. 2008, 11, 138-143.

31. Jolles, A.E.; Etienne, R.S.; Olff, H. Independent and competing disease risks: Implications for host populations in variable environments. Am Nat. 2006, 167, 745-757.

32. Schaaf, C.B.; Gao, F.; Strahler, A.H.; Lucht, W.; Li, X.; Tsang, T.; Strugnell, N.C.; Zhang, X.; Jin, Y.; Muller, J.P. First operational BRDF, albedo nadir reflectance products from MODIS. Remote Sens. Environ. 2002, 83, 135-148.

33. Reinecker, M.M.; Suarez, M.J.; Gelaro, R.; Todling, R.; Bacmeister, J.; Liu, E.; Bosilovich, M.G.; Schubert, S.D.; Takacs, L.; Kim, G.K.MERRA: NASA's modern-era retrospective analysis for research and applications. J. Clim. 2011, 24, 3624-3648.

34. Kruger, A. The influence of the decadal-scale variability of summer rainfall on the impact of El Niño and La Niña events in South Africa. Int. J. Climatol. 1999, 19, 59-68.

35. Anyamba, A.; Tucker, C.J.; Mahoney, R. From El Niño to La Niña: Vegetation response patterns over east and southern Africa during the 1997-2000 period. J. Clim. 2002, 15, 3096-3103. 
36. Saji N.H.; Goswami, B.N.; Vinayachandran, P.N.; Yamagata, T. A dipole mode in the tropical Indian Ocean. Nature. 1999, 401, 360.

37. Reason, C.; Mulenga, H. Relationships between South African rainfall and SST anomalies in the southwest Indian Ocean. Int. J. Climatol. 1999, 19, 1651-1673.

38. Reason, C. Subtropical Indian Ocean SST dipole events and southern African rainfall. Geophys. Res. Lett. 2001, 28, 2225-2227.

39. Reason, C.; Rouault, M. ENSO-like decadal variability and South African rainfall. Geophys. Res. Lett. 2002, 29, 161-164.

40. Mann, H.B. Nonparametric tests against trend. Econometrica. 1945, 1, 245-259.

41. Gilbert, R.O. Statistical methods for environmental pollution monitoring; John Wiley \& Sons: Toronto, Canada, 1987.

42. Kendall, M.G. Rank correlation methods; Griffin: London, United Kingdom,1975.

43. Lanzante, J.R., Resistant, robust and non-parametric techniques for the analysis of climate data: Theory and examples, including applications to historical radiosonde station data. Int. J. Climatol. 1996, 16, 1197-1226.

44. Pohlert, T. Non-parametric trend tests and change-point detection. 2018. Available online: https://cran.rproject.org/web/packages/trend/trend.pdf (accessed on 27 July 2018).

45. Torrence, C.; Compo, G.P. A practical guide to wavelet analysis. Bull. Am. Meteorol. Soc. 1998, 79, 61-78.

46. Jevrejeva, S.; Moore, J.; Grinsted, A. Influence of the arctic oscillation and El Niño-Southern Oscillation (ENSO) on ice conditions in the Baltic Sea: The wavelet approach. J. Geophys. Res. Atmo. 2003, 108, (D21), 4677, doi:10.1029/2003JD003417.

47. Grinsted, A.; Moore, J.C.; Jevrejeva, S. Application of the cross wavelet transform and wavelet coherence to geophysical time series. Nonlinear Proc. Geoph. 2004, 11, 561-566.

48. Zar, J.H. Biostatistical analysis; Upper Saddle River: New Jersey, USA, 1999.

49. Schulte, J.A.; Najjar, R.G.; Li, M. The influence of climate modes on streamflow in the Mid-Atlantic region of the United States. J. Hydrol. Reg. Stud. 2016, 5, 80-99.

50. Wilcox, R.R. Fundamentals of modern statistical methods: Substantially improving power and accuracy; Springer: New York, USA, 2010.

51. Carslaw, D.C.; Ropkins, K. Openair - an R package for air quality data analysis. Environ. Modell. Softw. 2012, 27, 52-61.

52. Mberego, S.; Gwenzi, J. Temporal patterns of precipitation and vegetation variability over Zimbabwe during extreme dry and wet rainfall seasons. J. Appl. Meteorol. Climatol. 2014, 53, 2790-2804.

53. Manatsa, D.; Mukwada, G.; Siziba, E.; Chinyanganya, T. Analysis of multidimensional aspects of agricultural droughts in Zimbabwe using the standardized precipitation index (SPI). Theor. Appl. Climatol. 2010, 102, 287-305.

54. Verbesselt, J.; Hyndman, R.; Newnham, G.; Culvenor, D. Detecting trend and seasonal changes in satellite image time series. Remote Sens. Environ. 2010, 114, 106-115.

55. Verbesselt, J.; Hyndman, R.; Zeileis, A.; Culvenor, D. Phenological change detection while accounting for abrupt and gradual trends in satellite image time series. Remote Sens. Environ. 2010, 114, 2970-2980.

56. Fitchett, J.M.; Grab, S.W. A 66-year tropical cyclone record for south-east Africa: Temporal trends in a global context. Int. J. Climatol. 2014, 34, 3604-3615.

57. Tabari, H.; Marofi, S.; Aeini, A.; Talaee, P.H.; Mohammadi, K. Trend analysis of reference evapotranspiration in the western half of Iran. Agric. For. Meteorol. 2011, 151, 128-136. 